\title{
Dynamic Geomorphology of the Kosi Fan in Consequence to a Mega- Avulsion Aided by Space Inputs and Hydraulic Modeling
}

\section{Panda PK $^{*}$ and Narasimham ML}

Department of Civil Engineering, Centurion University of Technology and Management, Odisha, India

*Corresponding author: Prafulla Kumar Panda, Department of Civil Engineering, Centurion University of Technology and Management, Odisha, India, Tel: +91-9438269572; E-mail: prafullapanda@cutm.ac.in

Rec date: March 12, 2018; Acc date: April 19, 2018; Pub date: April 23, 2018

Copyright: ( 2018 Panda PK, et al. This is an open-access article distributed under the terms of the Creative Commons Attribution License, which permits unrestricted use, distribution, and reproduction in any medium, provided the original author and source are credited.

\begin{abstract}
Several geomorphic processes are occurring on our planet, so it is always need to understand the geomorphic changes and evaluate the land form dynamics. The geomorphic evolution of any area can be obtained by detailed land form mapping. In the present study, an area in the parts of the Kosi basin has been selected for the study mainly using remote sensing data. Various fluvial land forms mapped and changes in course of the river have been evaluated. Digital enhancements of Landsat ETM+, IRS LISS-IV and Cartosat-1 are found to be quite useful in identification and mapping of fluvial features. The present study demonstrate the utility of remote sensing in examine the geomorphic evolution of the area. Geomorphic elements such as active channels, avulsion channel, water logged areas, sand bars, meander scar, minor active channels, paleo channels, dry channels etc., were mapped and combined all elements mega geomorphic units prepared such as hard rock terrain, piedmont zone, inactive flood plain, active flood plain, channel belt, minor active channel and its flood plain, fan surface and avulsion belt. Comparative study carried out for landscape as well as geomorphic evolution between prior to avulsion and post avulsion after the mega event (2008 flood). Remote sensing based geomorphic mapping of the parts of the Kosi basin for the pre and post- to avulsion images have brought interesting changes in the regional landscape in consequence of a large avulsion which occurred on August 18th, 2008. Major changes occurred in the main channel as well as outer channel. It has been estimated that approximately $511 \mathrm{sq} \mathrm{km}$ of agricultural land got converted into sandy areas (moist) making them barren for few years.
\end{abstract}

Keywords: Remote sensing; ETM+; LISS; Avulsion; Paleo channel; Meander scar

\section{Introduction}

Any sustainable landscape is a cumulative product of geomorphic processes operating over millennia. A geomorphic map portrays surficial features or landforms that record geologic processes on the earth's surface. Geomorphology is the science of studying the external expression and internal architecture of the planet earth. The geomorphic evolution of any area can be obtained by land form mapping and remote sensing data have immense potential in this respect. Satellite images are useful for a purpose as the land form features are very clearly depicted in synoptic view. This provides ample scope for visualizing the complexity of fluvial environment and dynamic geomorphology of an area. Keeping in this view, an attempt has been made in present study to trace the geomorphic evolution of the fluvial landscape in parts of the Kosi basin before and after of the mega event. The Kosi River is an important tributary of the Ganga in the eastern India (Figure 1) and has distinctive hydrological and sediment transport characteristics. The dynamics of the Kosi River, generally described as 'avulsive' shifts, has been well documented by previous workers and a preferentially westward movement of $150 \mathrm{~km}$ in the last 200 years has been recorded [1]. The movement of the river has not been gradual but of avulsive in nature (sudden change in the river course) originating from the nodal point [1]. A number of paleo channels on the satellite image of the Kosi basin testify the migratory behavior of the river. The river is typically braided in nature and has formed a very large alluvial fan due to a large supply of the sediments from the Himalaya and a generally aggradational regime. Further complication arises due to (a) very high rain fall in the catchment (1200-2000 mm in most parts) and (b) high seismicity in the hinter land causing landslides and large sediment production which subsequently fill up the basin. Various explanations for this unidirectional shift of the Kosi include sedimentation in braided stream, cone building activity, active tectonics, and auto cyclic and stochastic movements. The Kosi River has been responsible for some of the most devastating floods. It is also known as the "Sorrow of $\mathrm{t}$ Bihar" due to the frequent channel migration and extensive flood damage in this region. Unlike the previous westward avulsion, the 18th august 2008 avulsion of the Kosi River recorded an east ward jump of approximately $120 \mathrm{~km}$ which an order of magnitude higher than any single avulsive shift recorded in historical times $[2,3]$. The avulsion was triggered by a breach in the eastern afflux bund of the Kosi at Kusaha, $12 \mathrm{~km}$ upstream of the Kosi barrage. This avulsed channel reoccupied one of the paleo channels of the Kosi and about $80-85 \%$ flow of the river diverted into new course. The new course had a much lower carrying capacity; the water flowed like a sheet, $15-20 \mathrm{~km}$ wide and 120 $\mathrm{km}$ long. Interestingly, the new course did not join back the Kosi nor did this find through- drainages in to Ganga, as a result of which a very large area inundated/waterlogged. This single event affected more than 30 million people. Several lines of evidences coupled with field observation support that this event was a "mega avulsion" rather than a regular flood.

The continuing channel modification and change in the river course have got a greater implication on the geomorphic evolution processes. For a successful planning and management of resources it is essential to assess the signatures of the dynamic river systems and its 
surrounding environment. The present investigation is under taken to prepare geomorphologic map and their characteristics in parts of the Kosi river basin using satellite images.

The study area lies in between latitude of $86^{\circ} 38^{\prime} 48^{\prime \prime}$ to $87^{\circ} 8^{\prime} 41^{\prime \prime} \mathrm{N}$ and longitude of $26^{\circ} 6^{\prime} 15^{\prime \prime}$ to $26^{\circ} 42^{\prime} 50^{\prime \prime} \mathrm{E}$ (Figure 1). The river Kosi is the perennial in nature where as its tributaries are ephemeral. The study area is covered approximately $6063 \mathrm{sq} \mathrm{km}$ with hill terrain as well as thick alluvial sediments. These thick alluvial deposits occurred due to the aggradational process of river Kosi.

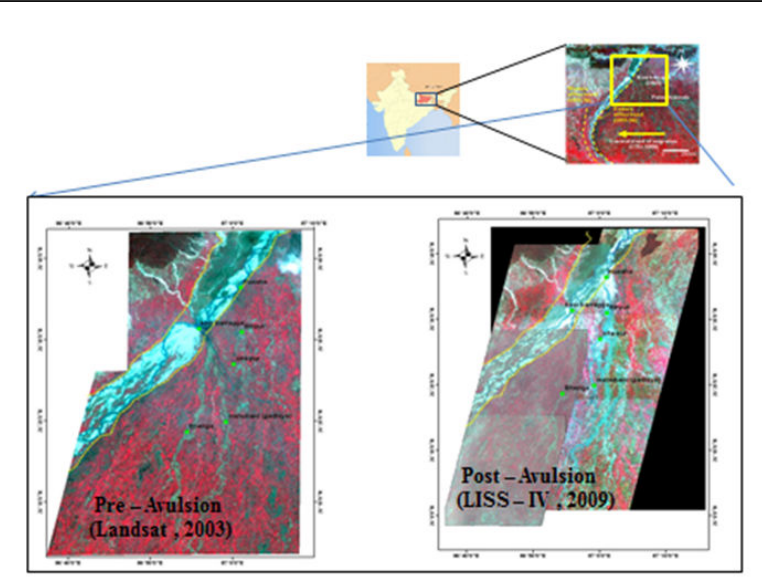

Figure 1: Image Showing Location of the Study Area.

\section{Data Sources and Methodology}

The present study is based on variety of data sets such as Landsat Enhanced Thematic Mapper Plus $\left(\mathrm{ETM}^{+}\right)$with spatial resolution of 30 $\mathrm{m}$, date of acquisition February 2003 and 5 scene of IRS Linear Imaging Self-Scanning Sensor - (LISS-4) corresponding to path-row $27096 / 35,27096 / 36,27778 / 41$ acquired in Jan 2009, 27096/37, $27778 / 43$ acquired in feb. 2009 with spatial resolution of $5.8 \mathrm{~m} .3$ scenes of Cartosat-1 images with spatial resolution of $2.5 \mathrm{~m}$. Topographic sheets from Survey of India, 1983 includes 72J and 72N (1:2, 50,000). The interpretations have been checked through selective field visit.

Landform have been mapped on the basis of (i) their size and shape (ii) superimposition of features, and (iii) their preservation and proximity. The above factors have helped to analyze land forms in the light of their physical appearances and occurrences which, in turn, have proved useful in understanding their genesis. Image interpretation needs systematic and frequent examination of the object presents in the image. The step by step procedure adopted for the preparation of geomorphic map shown in the Figure 2. The land forms marked within the hilly terrain includes hard rock terrain, piedmont surface, within the channel environment include active channel belt, active channel, sand bars. Land forms in the overbank includes active flood plain, active minor channel, paleo channel, meander scars, inactive flood plain, water logged areas, high moisture areas, avulsion belt, fan surface (Figures 3 and 4).

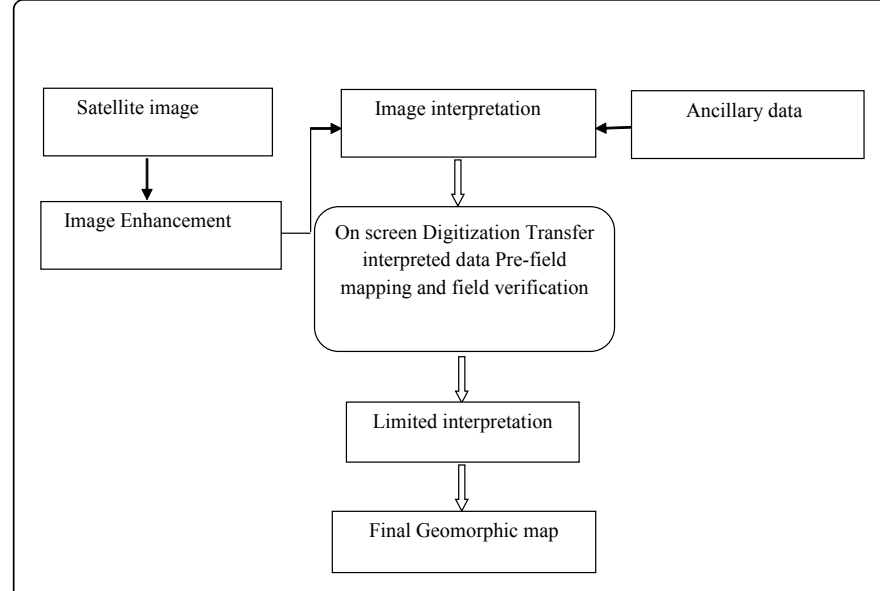

Figure 2: Steps under taken to prepare geomorphic land form changes.

\section{Dynamic Geomorphology of the Kosi Fan Aided by Satellite Remote Sensing}

\section{Geomorphic elements and major geomorphic units}

Geomorphology is the classification, description, nature, origin, and development of present landforms. This element describes the predominant geomorphic processes active in the Section that resulted in formation of the characteristic landforms. To understand the river avulsion and landform evolution in Kosi alluvial plain, a dynamic geomorphic mapping has been done on satellite images prior and post to avulsion. The mapping has been done in digital mode using the onscreen digitization in Arc Map GIS. Primarily, the processed images, maps were used and supplemented with information from topographic sheets and DEM. Thematic maps of geomorphic elements such as active channels, water logged areas, channel bars, meander scar, minor active channels, paleo channels, dry channels, wet channels etc., were mapped, and were overlain to get an integrated geomorphic map of the area. Each geomorphic element was coded in different colours and ID is given in the thematic map. The detailed geomorphic map of the study area prior to and post-avulsion are shown in Figures 3 and 4. Table 1 describe the different geomorphic elements and units mapped for both the periods. As shown in the Figure 3, the pre-avulsion map based on the satellite image of the year 2003 consists of seven geomorphic units namely active channel belt, active flood plain of major rivers, inactive flood plain, minor active channels and its flood plain, hard rock terrain, piedmont plain, fan surface. These major units are prepared based on the distribution of geomorphic elements and the understanding of the modern processes involved. Most of these units are mapped from the post-avulsion image as well but with some variation in their spatial distribution. In addition, an additional and distinctive unit, Avulsion deposit belt, mapped in the post-avulsion image covering a large part of the fan surface. The systematic description of each of these units on both the maps follows next along with field observation. 
Citation: Panda PK, Narasimham ML (2018) Dynamic Geomorphology of the Kosi Fan in Consequence to a Mega-Avulsion Aided by Space Inputs and Hydraulic Modeling. J Remote Sensing \& GIS 7: 238. doi:10.4172/2469-4134.1000238

Page 3 of 6

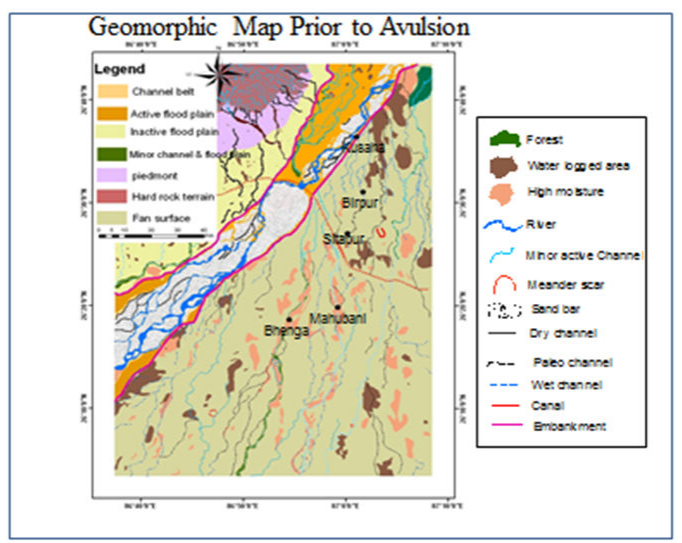

Figure 3: Showing various Geomorhic units and elements prior to Avulsion 2003.

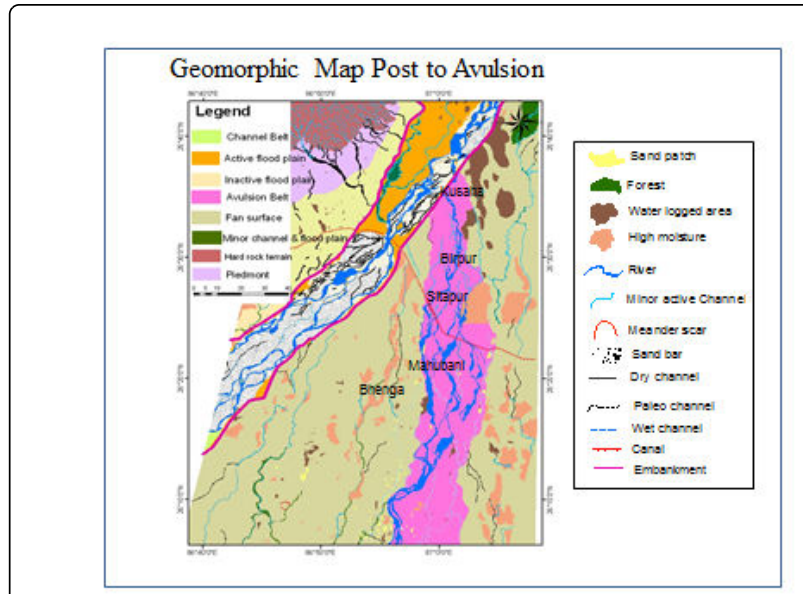

Fig.4 Showing various geomorphic units and elements post to avul sion in -2009

Figure 4: Image showing various Geomorphic Units and elements post to Avulsion in 2009.

\begin{tabular}{|c|c|c|}
\hline Geomorphic element & Geomorphic characteristics & Identification criteria on satellite images \\
\hline Active channel & $\begin{array}{l}\text { Active channel (AC): Area frequently or recently reworked by fluvial processes } \\
\text { during high flow events. The active channel includes only channel-like features } \\
\text { (i.e., elongated, appear to have been carved by flowing water); other water } \\
\text { bodies are classified within the flood plain. The area in the active channel is } \\
\text { occupied by water, bars, and exposed channel bed. This element defined as } \\
\text { the portion of the river and flood plain inundated both ends connects to the } \\
\text { main channel }\end{array}$ & $\begin{array}{l}\text { These features are identified from the satellite imagery due } \\
\text { to the dark blue to light blue colour. }\end{array}$ \\
\hline Channel bar & $\begin{array}{l}\text { Channel bars are the land forms in a river that begin to form when the } \\
\text { discharge is low and the river is forced to take route of less resistance by } \\
\text { means of flowing in location of lowest elevation. }\end{array}$ & $\begin{array}{l}\text { Due to its greenish and bright colour it is identified from } \\
\text { imagery }\end{array}$ \\
\hline Meander scar & $\begin{array}{l}\text { Meander scar is a geological feature formed by the remnants of a meandering } \\
\text { water channel. They are often formed during the creation of oxbow lakes. } \\
\text { These are the remnants of the highly sinuous paleo drainage system, which } \\
\text { were cut off from main channel. These are identified by arcuate shape, uniform } \\
\text { tone, isolated occurrences depressed relief characteristics. }\end{array}$ & $\begin{array}{l}\text { It is identified from the satellite imagery due to its dark } \\
\text { tone. It looks like a curvilinear stretches. }\end{array}$ \\
\hline Paleo channel & $\begin{array}{l}\text { Ancient drainage line of the stream of the river through which it might have } \\
\text { flown in the past. }\end{array}$ & $\begin{array}{l}\text { Identified from medium to dark tone, curvilinear pattern, } \\
\text { and uniform to continuing of older stream. Also it has been } \\
\text { identified from, in association with linear orientation of the } \\
\text { vegetation. }\end{array}$ \\
\hline Minor active channels & These are the important tributaries joined to the main stream. & These are identified from its dark to light blue color. \\
\hline Avulsion deposit & $\begin{array}{l}\text { Avulsion is the natural process by which flow diverts out of an established river } \\
\text { channel into a new permanent course on the adjacent flood plain. Avulsions } \\
\text { are primarily features of aggrading flood plains. Rivers can also avulse due to } \\
\text { the erosion of a new channel that creates a straighter path through the } \\
\text { landscape. This can happen during large floods in situations in which the slope } \\
\text { of the new channel is significantly greater than that of the old channel }\end{array}$ & $\begin{array}{l}\text { This is also identified from imagery due to its light green to } \\
\text { light gray tone. }\end{array}$ \\
\hline Water logged area & $\begin{array}{l}\text { These features are identified in the low depressed areas where stagnate water } \\
\text { bodies have been found }\end{array}$ & It is identified due to its dark tone in the image. \\
\hline
\end{tabular}

Table 1: The different geomorphic elements and units mapped for both the periods.

\section{Major geomorphic units}

Unit 1: Hard rock terrain: The part of the window at the NW corner consists of exposures of hard rock's with elevations ranging from $120 \mathrm{~m}$ to $220 \mathrm{~m}$. It has incised coarser drainage pattern. This is marked as a separate unit which displays a typical dendritic drainage and is highly vegetated. This unit covers an area of $100.59 \mathrm{sq} \mathrm{km}$ in this window. Several minor channels are draining from this elevated terrain join together to form a larger channel which ultimately feed the Kosi River. 
Unit-2: Piedmont surface: This unit, lying in an elevation range of $100 \mathrm{~m}$ to $120 \mathrm{~m}$, is characterized by a distinct topographic break close to the mountain front. As a consequence, the rivers draining out of the high mountains deposit most of the sediments around this region to form the piedmont plains covering an area of $86.37 \mathrm{sq} \mathrm{km}$ in the study area. This unit shows a very distinct tone on the image and characterized by a very low vegetation cover, parallel to sub-parallel drainage pattern with a low drainage density and a few patches of water logged areas are also noted.

As mentioned above, this unit marks the formation of larger channels at the foot of the elevated areas (Unit-2). Most of these channels appear dry on the satellite image (apparently to thick alluvial cover below the piedmont plains) but they are active during monsoon periods. One of the larger channels is the Mahuli River which has two major tributaries and the combined flow joins the Kosi River just upstream of the barrage. Interestingly, they join the Kosi system at obtuse angles $120^{\circ}$ may be due to embankment.

Unit 3: Active channel belt: This unit is defined by the active course of the major river Kosi and associated channel bar deposits. This unit constitutes the youngest geomorphic surface and occurs at an elevation range of $65 \mathrm{~m}$ to $90 \mathrm{~m}$. Channel surface is the youngest geomorphic surface and the associated channel bars are slightly elevated surface in this zone, which are often washed out by the water. Stable bars are covered by grass like vegetation and are little more elevated due to stacking of sediment each year during high water level. Active channels and associated sand bars are clearly visible on the FCC (Figure 1). The darker tones on the NIR band indicate the presence of deep water. The sand bars show a brighter tone on the FCC, moist bars exhibit very light blue shades and the vegetated bars show different shades of red. Total channel belt area covers an area of $338.131 \mathrm{sq} \mathrm{km}$.

Unit 4: Active flood plain of major rivers: The active flood plains, adjacent to the present-day major channel belts, define a geomorphic surface which is often flooded in monsoon period through overtopping by the river. Generally, in normal rivers this unit will be comparatively at higher elevation closer to the present day river but in avulsing rivers like Kosi this unit is at a lower elevation than the river, termed as super elevation. This unit is characterized by the presence of meander scars, minor channels, dry channels and water-logged areas on the satellite images and suggests recent channel activity on the flood plain. The meander scars with an arcuate shape are the remnants of a meandering water channel which were cut off from the main channel. These are low elevation regions and exhibit a darker tone. The tributaries joining the main channels are considered as the minor channels which show a darker to lighter blue tone on the FCC. In terms of topographic relationships, this unit ranges in elevation from $72 \mathrm{~m}$ to $83 \mathrm{~m}$. Approximately the area covered by the active flood plain is $274.169 \mathrm{sq}$ $\mathrm{km}$.

Unit 5: Inactive flood plain: This unit is presently beyond any major channel activity except that minor channels may sometimes remobilize sediments during heavy precipitation. This unit ranges in elevation from $76 \mathrm{~m}$ to $85 \mathrm{~m}$ which is higher than the active flood plain. Covering an area of $209.79 \mathrm{sq} \mathrm{km}$ in this window, this unit is recognized by the presence of typical flood plain features such as abandoned channels, dry streams, highly vegetated area (mostly agricultural land), water logged areas and high moisture zones. The water-logged patches are the low-lying areas where water gets stagnated and show distinct darker tones on the NIR band of the image. The dry streams are fairly continuous and sinuous and show a very bright tone on the image. The information from the NDVI map suggests that the region is highly vegetated, and we can say that those are high moisture areas.

Unit 6: Minor active channels and flood plain: Active minor channel belt and flood plains of minor rivers in the study area are much narrower as compared to the active major channel belt. Therefore, minor channels and their flood plains have been combined into one geomorphic unit. The active minor channels on the satellite image appeared as a line, so they could be visualized by applying low pass filter. These channels are continuous in nature and show darker tones on the image. Evidence of shifting of channel course is insignificant in this unit, but the channels actively transport water and sediment load throughout the year. These channels are perennial because they are fed by spring water throughout the year. This unit covering an area of $82.609 \mathrm{sq} \mathrm{km}$.

Unit 7: Fan surface: The remaining part of the study window to the east of the eastern embankment has been mapped as the fan surface covering an area of $1836.11 \mathrm{sq} \mathrm{km}$ in the study window. This unit is interminably flat (elevation varies from $43 \mathrm{~m}$ to $90 \mathrm{~m}$, lower than the active flood plain unit) and is primarily marked by the former channels of the Kosi river many of which are still active and flow for a large part of the year. Large patches of water-logged areas are conspicuous which probably mark low-lying back swamp areas associated with the former channels. Many of these areas have dried out but can still be picked up on the satellite images due to high moisture conditions. The paleo channels are recognized by medium to dark tone and are marked by the curvilinear orientation of vegetation along these. Adjacent to the eastern embankment widespread water logged areas probably represent the seepage through the embankment and this is confirmed in the field as well. Over the years, these seepages have combined to form a several well-defined channels on the fan surface and one of them is flowing along the eastern embankment. A small patch of forested area shows up in the NE corner of the window and the remaining parts are marked by widespread agricultural fields.

Unit 8: Avulsion belt: This is characterized by the presence of sand deposits and the active avulsion channels. This is a very unique feature observed in avulsing rivers (Figure 4 and from the field observation Figures $5 \mathrm{a}$ and $5 \mathrm{~b}$ ). These features show a very distinct variation in spectral characteristics as compared to other features in the study area. The sand deposits show a brighter tone while the channels show darker tone on the image. These features are formed by the deposition of sand during the avulsion process which occurs mainly in aggrading rivers. In the field it is observed that all the agricultural lands were filled with sand after the mega event (Figures $5 \mathrm{c}$ and $5 \mathrm{~d}$ ). Approximately the area covered by this unit is $511 \mathrm{sq} \mathrm{km}$.

\section{Hydraulic Modeling of the Avulsion Belt}

Flood control strategies of most of the Indian Rivers are primarily based on of its engineering solutions such as; Constructions of barrages, Dams and Embankments etc. It has also been observed in many cases that the catastrophe of flooding due to failure of these structures is far different than the normal flooding which occurs due to the high precipitation and runoff. Factors governing the normal flooding are manly dependent upon the amount of precipitation and the surface runoff response, thus it is quite possible and easy to predict the hydrographs of the flood waves at any point in the downstream. Apart from the normal flooding especially, in case of dam or embankments failure where the impounded water of the dam and river escape through the breach into the downstream. Usually in this 
scenario the magnitude of the floods wave increases many fold than the normal flooding and this makes it difficult to analyze with the common modeling approach which have worked so well for the precipitation runoff floods.

The DAMBRK model developed by U.S. National Weather Services (NWS) attempts to represent the current state-of-the-art in understanding of dam break and the use of hydrodynamic theory to predict the dam-break wave formation and downstream progression. The DAMBRK model consists of three functional parts for computation purpose:

- Description of the mode of dam failure,

- Computation of the time history of the outflow through the breach,

- Routing of the outflow hydrograph through the downstream valley.

The basic component of the DAMBRK model is a dynamic routing technique for determining the modifications to the dam break flood wave as it advances through the downstream valley, including its travel time and resulting water surface elevations. The dynamic routing component of the model is based on a weighted four-point, nonlinear finite-difference solution of the one- dimensional "Saint-Venant" equations of unsteady flow which allows variable time and distance steps to be used in the solution procedure. Provisions have also been included for routing the various types of flow like supercritical flows, subcritical flows. The model also incorporates the study of effects of downstream obstructions such as road-bridge embankments culverts etc., in the calculations.

In present study an attempt has been made to simulate the embankment breach scenario for the Kosi River of Bihar (India) and Nepal. Recently on 18 august 2008 the Kosi River took a shift of $\sim 120$ $\mathrm{km}$ eastward, triggered by the breach of eastern embankment at Kusaha in Nepal at location $12 \mathrm{~km}$ upstream of the Kosi barrage. The breach at Kusaha was 1500 meters wide and it has also been reported that the velocity of water at the time of breach was $1 \mathrm{~m} / \mathrm{s}$. interestingly; the breach occurred at very low discharge 144,000 cusecs against its design discharge of 950,000 cusecs. In this study we have used the cross-sectional data obtained from SRTM DEM of 90 meters resolution and run the model to calculate the water surface elevation at different location and its travel time. Further the water surface elevations at different cross-sections were used to generate the final inundation map. We have also done the Sensitivity analysis to observe the effect of different manning's value and time to breach on the water surface elevation results and it is fund that the surface roughness do not have much effect however, breaching time influences the results significantly.

\section{Discussion}

\section{Major landform changes in consequence to the August 2008 avulsion}

Remote sensing based geomorphic mapping of the Kosi basin for the pre and post- to avulsion images have brought interesting changes in the regional landscape in consequence of a large avulsion which occurred on August 18th, 2008. Major changes occurred in the main channel as well outer channel. The upstream of the river was flowing eastwards (Figure 6a) during 2003. However due to heavy sedimentation and formations of large sand bars along the main channel, the river flow shifted towards east (Figure 6b). It can be observed from the satellite image the flow direction upstream of the breach location had also gradually changed prior to breach, providing a more erosive angle of attack against the eastern embankment. The river flow become almost perpendicular in the month prior to the breach, thrusting pressure directly on the eastern embankment [4]. The change in the angle of attack upstream of the breach could be surface a manifestation of the sub surface structural movement, as the higher Himalayas and the foot hill zone through which Kosi river emerges in to the plains near Charta constitutes a tectonically active zone $[5,6]$. Approximately $8 \%$ increase in the channel belt area has also been observed in the post-avulsion image, which is attributed to bank erosion in the intervening period.

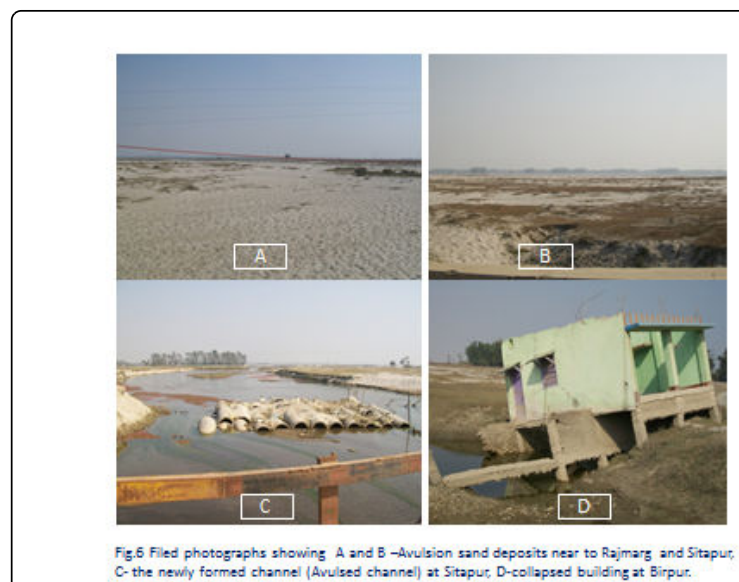
Fis. 6 Filed photographs showing A and B -Avulsion sand deposits near to Rajmarg and Sitap
C- the newhy formed channel (Avulsed channel) at Stapur. D-collapsed building at Birpur.

Figure 5: Filed photographs showing $\mathrm{A}$ and $\mathrm{B}$ Avulsion sand deposits near to Rajmarg and Sitapur; C-the newly formed channel at sitpur; D-Collapsed building at Birpur.

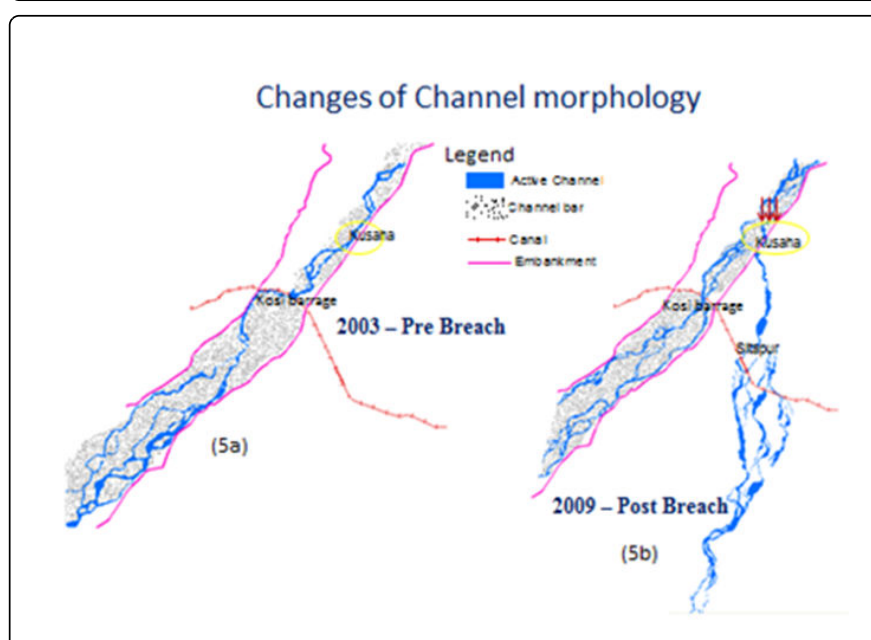

Figure 6: Changes of the channel morphology for the both period: a) 2003-Pre-Breach b) 2009-Post-Breach.

It has been noticed that in outer side of the channel most prominent, dramatic and drastic change is recognition of extensive avulsion belt (Unit-8) within the fan surface (Unit-7) primarily recognized by widespread sand deposition. Not much change is 
Citation: Panda PK, Narasimham ML (2018) Dynamic Geomorphology of the Kosi Fan in Consequence to a Mega-Avulsion Aided by Space Inputs and Hydraulic Modeling. J Remote Sensing \& GIS 7: 238. doi:10.4172/2469-4134.1000238

Page 6 of 6

observed on the western side of the study area in the post-avulsion image except for a few paleochannels which became active. Another interesting observation is that many of the paleochannels on the active flood plain as well as on the fan surface have been reactivated after the avulsion apparently due to re-establishment of their longitudinal connectivity during the flooding which followed the avulsion. Two of these channels passing through Supal, Madhepura and Saharsha district, formed the main conduits for the Kosi discharge. Further, a large part of the avulsion belt occupies the land which was the agricultural land prior to the avulsion. It has been estimated that approximately $511 \mathrm{sq} \mathrm{km}$ of agricultural land got converted into sandy areas (moist) making them barren for few years.

\section{Summary and Conclusion}

Satellite based observations show that the Kosi River is very dynamic in nature and the main channel of the Kosi shifted widely across several kilometers. The Kosi River was flowing very close to the protective eastern embankment and the angle of attack of the Kosi River upstream of the breach had become almost perpendicular in the month prior to the breach, thrusting pressure directly on the eastern embankment which subsequently led to breaching event. Remote sensing based geomorphic mapping of the parts of the Kosi basin for the pre and post-avulsion images have brought interesting changes in the regional landscape in consequence of a large avulsion which occurred on August 18th, 2008. The most prominent, dramatic and drastic change is the recognition of in channel as well as in the outer channel extensive avulsion belt (Unit-8) within the fan surface (Unit-7) primarily recognized by widespread sand deposition. A large part of the avulsion belt occupies the land which was the agricultural land prior to the avulsion. It has been estimated that approximately $511 \mathrm{sq}$ $\mathrm{km}$ of agricultural land got converted into sandy areas (moist) making them barren for few years.

\section{References}

1. Wells NA, Dorr Jr JA (1987) Shifting of the Kosi river, northern India. Geology 15: 204-207.

2. Sinha R, Bapalu GV, Singh LK, Rath B (2008) Flood risk analysis in the Kosi river basin, north Bihar using multi-parametric approach of Analytical Hierarchy Process (AHP). Indian Journal of Remote Sensing 36: 293-307.

3. Sinha R (2009) The Great avulsion of Kosi on 18 August 2008. Current Science 97: 429-433.

4. Bhatt CM, Rao GS, Manjushree P, Bhanumurty V (2010) Space based disaster Management of 2008 Kosi Floods, North Bihar, India. Journal of the Indian Society of Remote Sensing 38: 99-108.

5. Agrawal RP, Bhoj R (1992) Evolution of Kosi river fan, India: Structural implication and geomorphic significance. Int J Remote Sensing 13: 1891-1901.

6. Sinha R, Vikranta J, Prasad BG, Ghosh S (2005) Geomorphic Characterization and diversity of the fluvial systems of the Gangetic plains. Geomorphology 70: 207-225. 